\title{
Simultaneous but not independent anisomycin infusions in insular cortex and amygdala hinder stabilization of taste memory when updated
}

\author{
Paola García-DeLaTorre, Carlos J. Rodriguez-Ortiz, Jose L. Arreguin-Martinez, \\ Paulina Cruz-Castañeda, and Federico Bermúdez-Rattoni ${ }^{1}$ \\ Departamento de Neurociencias, Instituto de Fisiología Celular, Universidad Nacional Autónoma de México, México Distrito \\ Federal 04510, México
}

\begin{abstract}
Reconsolidation has been described as a process where a consolidated memory returns to a labile state when retrieved. Growing evidence suggests that reconsolidation is, in fact, a destabilization/stabilization process that incorporates updated information to a previously consolidated memory. We used the conditioned taste aversion (CTA) task in order to test this theory. On the first trial, the conditioned stimulus (CS) (saccharin) was associated to the unconditioned stimulus (US) ( $\mathrm{LiCl}$ injection), and as a result, aversion to saccharin was obtained. The following day, animals were injected with anisomycin in either the insular cortex (IC), central amygdala (CeA), basolateral amygdala (BLA), or simultaneously in IC and $\mathrm{CeA}$ or IC and BLA, and a second CTA trial was carried out in which updated information was acquired. Animals were tested $24 \mathrm{~h}$ later. When protein synthesis was inhibited in either the IC or $\mathrm{CeA}$, consolidation was affected and previously consolidated memory was unimpaired. However, when both the IC and $\mathrm{CeA}$ were simultaneously anisomycin injected, the previously consolidated memory was affected. After repeated association trials, protein synthesis inhibition in the IC and CeA did not have an effect on taste memory. These results suggest that the IC and the CeA are necessary for taste-aversion consolidation, and that both share the previously consolidated memory trace. In addition, our data demonstrated that protein synthesis in either the IC or the CeA suffices to stabilize previously consolidated taste memory when destabilized by incorporation of updated information.
\end{abstract}

[Supplemental material is available online at http://www.learnmem.org.]

The consolidation theory proposes that through new protein synthesis recently acquired memories are strengthened over time into a stable long-term memory trace (McGaugh 1966, 2000; Davis and Squire 1984). Nevertheless, it had been implied that after consolidation, amnesic agents could no longer affect memory. However, it is now known that when reactivated, consolidated memory regains sensitivity to these agents and requires of protein synthesis once again to be retained in long-term storage (Sara 2000; Suzuki et al. 2004). This process is known as reconsolidation (Nader et al. 2000 ) and has been studied in various memory tasks and brain structures (for review, see Dudai and Eisenberg 2004). The term reconsolidation has been challenged and seems inadequate, since recent evidence indicates that this process is not a faithful recapitulation of consolidation (Dudai 2006). On this matter, it has been demonstrated that consolidation and reconsolidation share some molecular mechanisms but differ in many others (for review, see Dudai and Eisenberg 2004). For example, BDNF (brain-derived neurotrophic factor) in the hippocampus is required for consolidation of contextual fear conditioning, but not for reconsolidation (Lee et al. 2004). On the other hand, PKA in the basolateral amygdala (BLA) is required for both mechanisms in a conditioned taste aversion (CTA) task (Koh and Bernstein 2003).

Furthermore, we have proposed that reconsolidation is a process that incorporates relevant information to a previously consolidated memory trace (Sara 2000; Rodriguez-Ortiz et al. 2005,

'Corresponding author.

E-mail fbermude@ifc.unam.mx; fax (525) 622-5607.

Article is online at http://www.learnmem.org/cgi/doi/10.1101//m.1356509.
2008). When memory updating occurs, previously stored memory is destabilized (Lee 2008) and can therefore be affected by protein synthesis blockers. Thus, when behavior has reached an asymptotic level and no further learning is evident, previously consolidated memory remains stable and is resistant to amnesic treatments (Rodriguez-Ortiz et al. 2005).

CTA is a convenient task to investigate reconsolidation mechanisms in an aversive motivated learning protocol. In this paradigm, rats are presented with a taste (saccharin), which acts as the conditioned stimulus (CS). Then, gastric malaise is induced with a lithium chloride injection acting as the unconditioned stimulus (US). The outcome is a decreased consumption of saccharin on the test day as a result of the CS-US association. The task can be acquired in a single trial, and the resulting aversive memory can be tested several days later. Several reports indicate that CTA is subserved by the insular cortex (IC) (Dunn and Everitt 1988; Rosenblum et al. 1993; Escobar et al. 1998; Yasoshima and Yamamoto 1998) and the amygdala (Yamamoto and Fujimoto 1991; Bahar et al. 2004; Yamamoto 2007).

It has been postulated that memories depend on a neural representation of the taste that probably remains stored in several brain regions in parallel; this neural representation has been called the taste memory trace (Bures et al. 1998). In this regard, we have previously demonstrated that for taste aversion memory trace formation the cholinergic activity in both the IC and amygdala is necessary. Thus, N-methyl-D-aspartate (NMDA)-induced lesions into the nucleus basalis magnocellularis have a significant disruption in the acquisition of taste aversion, causing a considerable cholinergic activity reduction in both the amygdala and the IC 
(Gutiérrez et al. 1999). Interconnection between the amygdala and the IC have been described using retrograde and bidirectional tracers. It was found that the agranular and dysgranular parts of the insula have prominent connections with the amygdala, which could be mediating aversively motivated behaviors (Höistad and Barbas 2008). In this regard, Escobar and Bermúdez-Rattoni (2000) reported that tetanic stimulation of the BLA induces long-term potentiation (LTP) in the IC, which enhances the retention of CTA. Similarly, it has been demonstrated that intra-amygdala applications of glutamate enhances taste aversion memory, and this effect is blocked by infusions of an NMDA antagonist in the IC (Miranda et al. 2002; Ferreira et al. 2005). Protein synthesis has been found to be a necessary process in the IC and amygdala in order for CTA memory consolidation to occur. Bahar et al. $(2003,2004)$ found that protein synthesis inhibition in the CeA, but not in the BLA, disrupted CTA consolidation, but infusions in either of these nuclei of the amygdala did not affect CTA memory reconsolidation. All of these results suggest that for the formation and consolidation of aversive taste memory a dynamic interaction between the amygdala and the IC is required.

Therefore, the following experiments were designed to reveal the contribution of the IC and the amygdala in consolidation and reconsolidation of CTA. We used a repeated trials protocol that allows incoming information to be incorporated in each acquisition trial (Duvarci and Nader 2004). In all experiments, protein synthesis inhibition was obtained by microinfusions of anisomycin in the IC, BLA, or CeA, as well as simultaneous injections in the IC and CeA or IC and BLA.

\section{Results}

\section{Histological analysis}

After histological analysis, the following $n$ for each group resulted from the correct implants: IC-V, $n=30$, IC-A, $n=32$; CeA-V, $n=26$, CeA-A, $n=27$; BLA-V, $n=12$, BLA-A, $n=12$ (see Fig. 2, below); IC+CeA-V, $n=22$, IC+CeA-A, $n=21$; IC+BLA-V, $n=19$, IC+BLA-A, $n=27$ (see Fig. 3, below); and IC+CeA-V, $n=18$, IC+CeA-A, $n=15$ (see Fig. 4, below). Figure 1 shows a scheme of the cannula implants for the mentioned groups.

\section{Anisomycin infusions in the IC or CeA but not in the BLA, impair CTA consolidation}

To determine whether the IC, CeA, or BLA participate in stabilization of CTA memory under updating conditions, we used the protein synthesis inhibitor anisomycin as the consolidation blocker. The drug was infused $1 \mathrm{~h}$ before the second CTA acquisition. A control group was infused with ACSF for each structure tested. An ANOVA having repeated measures analysis showed differences among groups $\left(F_{(5,133)}=3.70 ; P<0.05\right)$, and days $\left(F_{(5,10)}=372.92 ; P<0.01\right)$, and a significant day per group interaction $\left(F_{(5,266)}=5.82 ; P<0.01\right)$.

When protein synthesis was quenched in the IC, consolidation of CTA was impaired (Fig. 2). A post-hoc analysis showed intake differences between IC-V and IC-A groups $(P<0.05)$. Furthermore, a paired $t$-test revealed an expected reduction in consumption between injection and test days $\left(t_{(29)}=3.71, P<0.05\right)$ in IC-V rats, while no intake differences were found in the IC-A group $\left(t_{(31)}=1.59, P=0.1213\right)$, reflecting memory consolidation impairment.

Similarly, when anisomycin was applied into the CeA, memory consolidation was impaired (Fig. 2). Significant differences were found in the test day between CeA-V and CeA-A animals as shown by a post-hoc analysis $(P<0.05)$. Similar to the results obtained for the IC, a paired $t$-test for injection and test days revealed no differences for the CeA-A group $\left(t_{(26)}=-0.12\right.$, NS), and a significant lower intake for the CeA- $\mathrm{V}$ group on test day $\left(t_{(25)}=7.42, P<0.01\right)$.

Finally, when anisomycin was administered in the BLA, there was no impairment of long-term memory (Fig. 2). Control and anisomycin-infused animals showed strong taste aversion; a posthoc analysis test showed no significant differences on test day (NS). Consistently, a paired $t$-test for injection and test days revealed that BLA-V and BLA-A groups had a significant intake reduction $\left(t_{(11)}=5.04, P<0.05 ; t_{(11)}=6.92, P<0.01\right.$, respectively).

Data obtained with protein synthesis inhibition in each region is shown in Figure 2. These results point to the fact that protein synthesis is required in either IC or CeA in order to consolidate information learned on a second taste aversion trial. However, protein synthesis in the BLA seems unnecessary to store CTA memory in the long term.

\section{Concurrent anisomycin infusions in the IC and $\mathrm{CeA}$ impair previously consolidated memory}

We observed consolidation impairment when protein synthesis was inhibited in the IC or CeA, but we did not reveal an effect on previously consolidated memory under conditions where memory was updated. Therefore, in an attempt to reveal reconsolidation of CTA when learning is attained, we bilaterally microinfused anisomycin in the IC together with bilateral injections in the CeA or BLA (Fig. 3). An ANOVA with repeated measures showed differences among groups $\left(F_{(3,85)}=9.52 ; P<0.01\right)$, days $\left(F_{(3,6)}=177.09\right.$; $P<0.01)$, and a significant day group interaction $\left(F_{(3,170)}=11.97 ; P<0.01\right)$. The post-hoc analysis with Fisher's test revealed that consumptions of IC+CeA-A on test day were significantly higher when compared with IC+CeA-V $(P<$ $0.01)$ and IC+BLA-A $(P=0.0168)$. The IC+BLA-A group itself showed a significant consumption increase when compared with IC+BLA-V $(P<0.01)$ as seen in Figure 3 . A paired $t$-test revealed an increase in consumption between the second acquisition and test days for the IC+CeA-A group $\left(t_{(20)}=-2.187, P<0.05\right)$ suggesting that the previously consolidated memory trace (CTA1) was affected. However, no difference in consumption was observed for the IC+BLA-A group $\left(t_{(26)}=0.0003, P=0.999\right)$, which did not consolidate the second trial. A significant
Figure 1. Histology. Schematic drawings show the cannulae position for each group; the dots indicate the aimed at structure: insular cortex $(I C)(A)$, basolateral amygdala $(B L A)(B)$, central amygdala $(\mathrm{CeA})(C), \mathrm{IC}$ and $\mathrm{CeA}(D)$, and IC and BLA $(E)$. Representative photomicrographs show the location of infusion injector tips in the corresponding structures: IC $(F)$, BLA $(G)$, and CeA $(H)$.

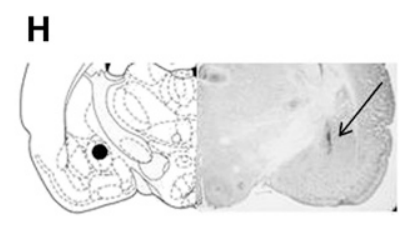




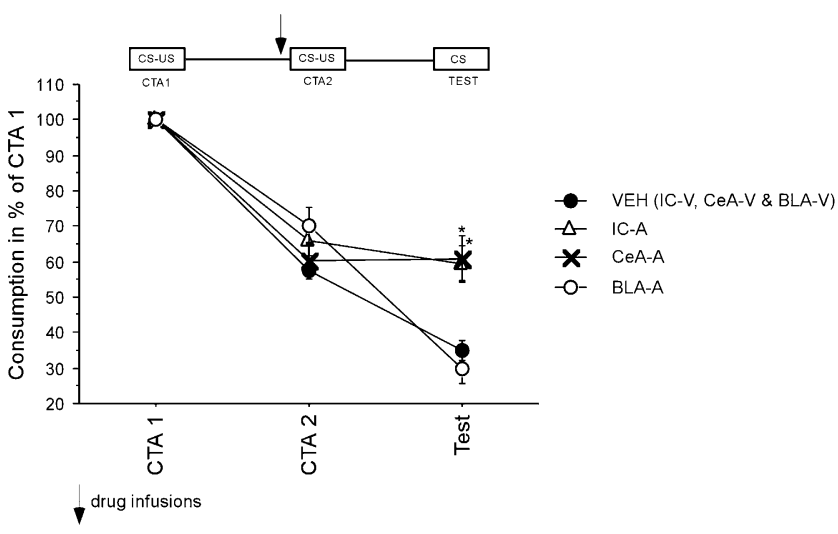

Figure 2. Protein synthesis inhibition on single structures. The top of the figure has a schematic representation of the protocol used in these experiments. Intracerebral injections were given $1 \mathrm{~h}$ before the second acquisition of CTA, a test was performed $24 \mathrm{~h}$ after. Each acquisition consisted of a CS (saccharin)-US ( $\mathrm{LiCl}$ ) association. When injected in either the IC (triangles) or CeA (crosses), anisomycin impaired consolidation of CTA. Anisomycin injections in the BLA (white circles) did not affect aversive memory. VEH (black circles) group represents injections of vehicle solution (ACSF) in either of the studied structures. $\left(^{*}\right) P<0.05$.

decrease in consumption was observed in the IC+CeA-V and IC+BLA-V groups $\left(t_{(21)}=7.26, P<0.01 ; t_{(18)}=7.22, P<0.01\right.$, respectively), indicating that the second trial was acquired.

\section{Anisomycin injections in both the IC and $\mathrm{CeA}$ in a behavioral asymptote do not affect memory}

In order to demonstrate that protein synthesis inhibition in the IC and CeA can only impair memory when new information is acquired, we infused anisomycin before the fifth CTA acquisition, when aversive behavior has reached an asymptotic level. Thus, as shown in Figure 4, inhibition of protein synthesis at this point did not affect taste memory at all. A repeated-measures ANOVA showed no differences between groups $\left(F_{(1,30)}=0.11 ; P=0.7389\right)$, although there were differences among days $\left(F_{(1,5)}=733.25 ; P<\right.$ $0.01)$, but no interaction $\left(F_{(1,150)}=0.69 ; P=0.6252\right)$. Post-hoc analysis with Fisher's test revealed that consumptions on the fifth acquisition and test days were similar and revealed no significant differences between groups. The body weight for all animals across the experimental days increased, since at the beginning the mean for all animals was $300.8 \mathrm{~g}$, and at the end the mean was $351.3 \mathrm{~g}$.

\section{Discussion}

Protein synthesis inhibitors are known to block memory consolidation in a variety of memory paradigms (Dudai 2002). Furthermore, it has been suggested that protein synthesis occurs more than once for long-term memory maintenance; this process when dependent on reactivation, has been referred to as reconsolidation (Nader et al. 2000; Dudai 2004; Tronson and Taylor 2007). As mentioned, reconsolidation is not a faithful recapitulation of consolidation, and it has been demonstrated that this process incorporates new information to a previously consolidated trace (Rodriguez-Ortiz et al. 2005, 2008; Eschenko et al. 2006; Morris et al. 2006; Hupbach et al. 2007; Rossato et al. 2007; Lee 2008). The present study describes memory reconsolidation as part of the updating process of CTA memory. In this regard, it has recently been reported that previously consolidated memory undergoes a temporal destabilization that allows new incoming information to be integrated to the memory through a protein degradation and protein synthesis-dependent process (Lee 2008).
We have proposed that when new information is capable of strengthening or altering previously consolidated memory, a protein synthesis-dependent process is initiated to allow incoming material to be integrated to a pervious memory trace (RodriguezOrtiz et al. 2005, 2008). For incorporation of information, previously consolidated memory is destabilized, making memory temporarily susceptible to disruption by amnesic treatments. On the other hand, when no new information is presented, memory cannot be disrupted. Accordingly, in the present study, after repeated association trials, protein synthesis inhibition in the IC and CeA did not have an effect on taste memory. Nevertheless, it should be pointed out that with overtrained memories it can be more difficult to trigger reconsolidation (Nader and Hardt 2009). For example, in contextual fear conditioning, strong memories require a longer reactivation in order for reconsolidation to be triggered (Suzuki et al. 2004). Accordingly, it cannot be stated that overtrained memories are a true boundary condition for reconsolidation induction. Thus, further experiments are needed to determine whether an asymptotic level of behavior in CTA does prevent reconsolidation or not.

Previous reports have shown that anisomycin infusions into the IC or CeA disrupt memory consolidation of CTA (Rosenblum et al. 1993; Bahar et al. 2003). However, independent anisomycin injections in the CeA or BLA do not impair reconsolidation of CTA (Bahar et al. 2004), although systemic anisomycin injections do (Gruest et al. 2004). This latter result could be explained by the fact that both structures, the IC and CeA, have to be protein synthesis inhibited at the same time to impair stabilization of the previously consolidated trace when reactivated. Our results could explain why systemic injections disrupt CTA reconsolidation and not independent infusions in either nucleus of the amygdala. However, it has been suggested that anisomycin when applied into the IC can affect CTA memory reconsolidation (Eisenberg et al. 2003; Rodriguez-Ortiz et al. 2005). In the latter study, anisomycin was injected in the IC when saccharin was associated to aversion after several presentations of the same taste without noxious

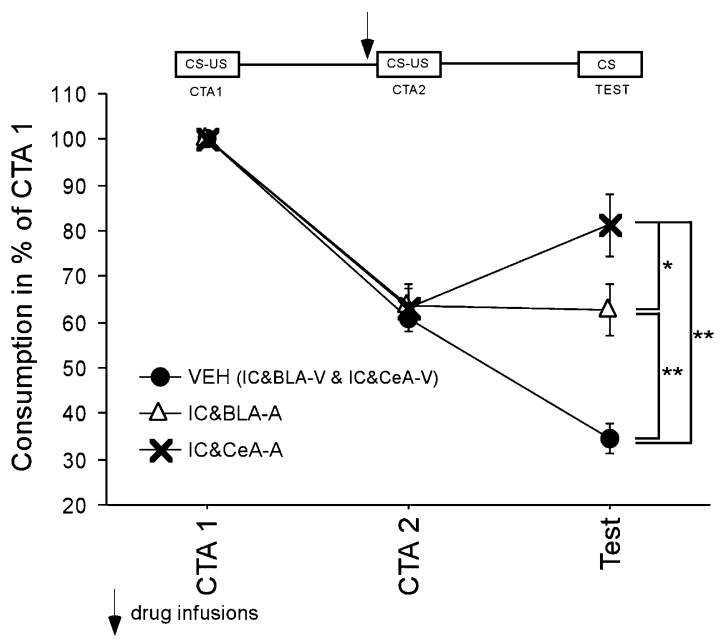

Figure 3. Protein synthesis inhibition in two structures at the same time. On top of the figure is a representation of the protocol used in these experiments. Intracerebral infusions were performed $1 \mathrm{~h}$ before the second CTA acquisition. The test consisted of saccharin presentation $24 \mathrm{~h}$ after injections. CS (saccharin)-US ( $\mathrm{LiCl}$ ) association was given in each acquisition. Anisomycin injections in the IC and CeA (crosses) disrupted the previously consolidated trace. When anisomycin was infused in the IC and BLA (triangles) only incoming aversion was affected. VEH group stands for injections of vehicle solution (ACSF) at the same time in the IC and one of the nuclei of the amygdala. $\left(^{* *}\right) P<0.01,\left(^{*}\right) P<0.05$. 


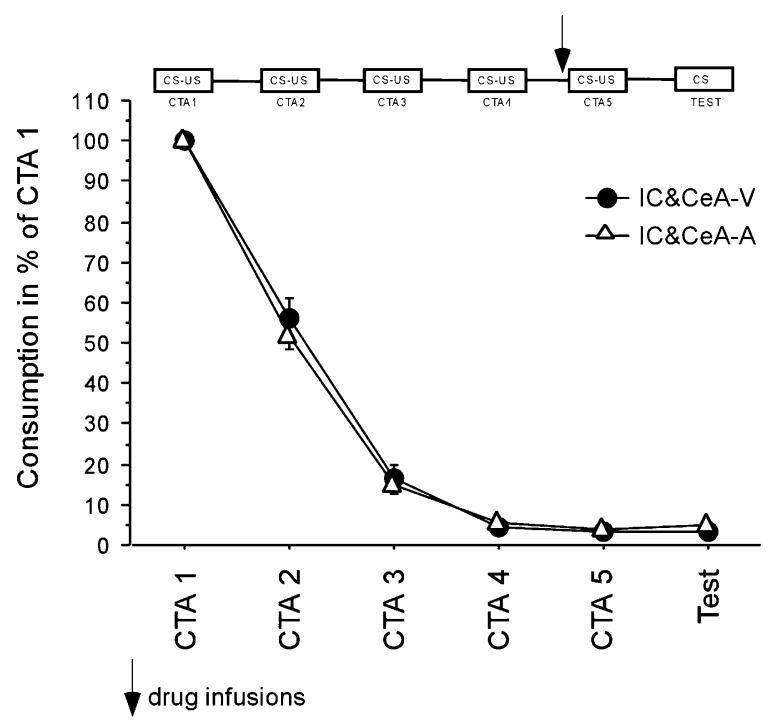

Figure 4. Protein synthesis inhibition in IC and $\mathrm{CeA}$ on behavioral asymptote. A schematic representation of the protocol used in this experiment is presented on top of the figure. Anisomycin $(\mathrm{Cl}+\mathrm{CeA}-\mathrm{A})$ or ACSF solution $(\mathrm{Cl}+\mathrm{CeA}-\mathrm{V})$ was injected $1 \mathrm{~h}$ before the fifth acquisition and a test was performed $24 \mathrm{~h}$ later. CS (saccharin)-US (LiCl) association was given on every acquisition day. When anisomycin was infused after behavior had reached a plateau, memory was not affected. No differences were observed between vehicle (black circles) and anisomycin-treated (triangles) animals.

consequences. Under that protocol, competition for the control of behavior was established between safe and aversive taste memory traces. In the test, rats drank significantly more saccharin solution compared with the previous presentation reflecting disruption of aversive taste memory. However, it is not clear whether the observed increment in consumption was due to impairment of reconsolidation or to disruption of incoming aversive memory that allowed overcoming expression of the dominant memory trace, i.e., safe saccharin. Similarly, Eisenberg et al. (2003) trained rats to choose between water and an aversive taste. After aversive memory reactivation the authors infused anisomycin in the IC and on test animals displayed disruption of the aversive trace by drinking more of the familiar water. However, in that study it is not possible to differentiate between effects on reconsolidation or overexpression of the dominant behavior (water preference).

In the present study, we confirmed that protein synthesis in the IC and CeA are indispensable to consolidate taste aversion memory, revealing that both structures participate in the formation of the aversive taste memory trace. Moreover, protein synthesis blockade in the CeA, BLA, or IC, independently, did not disrupt reconsolidation. The remarkable point from our results is that when both the IC and CeA were infused with anisomycin at the same time, on behavioral updating conditions, the previously consolidated trace was partially disrupted. These results suggest that taste aversion memory is simultaneously stored in the IC and $\mathrm{CeA}$, and that protein synthesis in one of these structures is enough to maintain the previously consolidated memory over time when destabilized by incorporation of updated information.

It is not new that several structures participate in taste memory consolidation. Concordantly, in our laboratory we have demonstrated behavioral enhancement of taste aversion by cortical LTP induction (high-frequency stimulation in the amygdala) or pharmacological (intra-amygdala applications of glutamate) stimulation of the amygdala. The observed facilitation of CTA induced by amygdala electrical or chemical stimulation was reversed by cortical infusions of NMDA receptor antagonist (Escobar et al.
2002; Miranda et al. 2002; Ferreira et al. 2005). Furthermore, it has been demonstrated that simultaneous electrical recordings of the amygdala and IC during CTA encoding show significant enhancement of functional connectivity between these two structures (Grossman et al. 2008). Accordingly, the present results suggest that both the amygdala and IC are important to consolidate and maintain the aversive taste memory trace for a long term when updated. Thus, it seems that a putative dialog between the amygdala and the IC is involved in CTA memory formation and updating. Similarly, it has been shown that contextual fear conditioning reconsolidation depends on more than one structure, i.e., the hippocampus and BLA (Huff and Rudy 2004). Thus, protein synthesis inhibition in only one of these structures is enough to damage reconsolidation, whereas for CTA, both the CeA and the IC are required. In this regard, a multiple-trace theory has been proposed (Nadel and Moscovitch 1997; Bontempi et al. 1999), which states the creation of multiple traces from a single memory that are interacting between structures. Our results suggest that a multipletrace consolidation of CTA in the IC and CeA could be taking place. This theory could explain why protein synthesis in both structures is required when memory is reactivated.

Numerous reports aimed to study consolidation or reconsolidation have used anisomycin as the protein synthesis inhibitor. In this regard, Gold (2007) has recently proposed that memory impairments observed when anisomycin is infused are not directly related to inhibition of protein synthesis, but rather to increments in neurotransmitters release. Although we cannot discard the fact that these alterations in neurotransmitters release did occur under our protocols and that they provide some contribution to our observed effects on memory, this possibility seems unlikely since we failed to see any effects on taste retention on the days of injection in anisomycin-infused animals. In addition, it could be argued that the observed disruption in consolidated memory by simultaneous anisomycin infusions in the IC and CeA was due to the larger volume of drug injected; however, similar injections in the IC and BLA did not produce the same effect; hence, this possibility seems unlikely.

In conclusion, we found that two important structures for CTA, the IC and CeA, are required to form the aversive memory trace. Both structures participate in CTA consolidation, and protein synthesis in only one of these regions is sufficient to stabilize previously consolidated CTA memory in the long term when relevant information is acquired. These results support our hypothesis that previously consolidated memory is destabilized to update memory, and only when new information is acquired can previously consolidated memory be altered.

\section{Materials and Methods}

\section{Subjects}

Male Wistar rats weighing 250-280 g, from the Instituto de Fisiología Celular breeding colony, were caged individually at $22^{\circ} \mathrm{C} \pm 2{ }^{\circ} \mathrm{C}$ in a 12 -h light/12-h dark cycle. Food was available ad libitum.

\section{Drugs}

The protein synthesis inhibitor anisomycin was obtained from Sigma-Aldrich. The drug was dissolved in artificial cerebral spinal fluid (ACSF: $\mathrm{NaCl} 125 \mathrm{mM}, \mathrm{KCl} 5 \mathrm{mM}, \mathrm{NaH}_{2} \mathrm{PO}_{4} \mathrm{H}_{2} \mathrm{O} 1.25 \mathrm{mM}$, $\mathrm{MgSO}_{4} 7 \mathrm{H}_{2} \mathrm{O} 1.5 \mathrm{mM}, \mathrm{NaHCO}_{3} 26 \mathrm{mM}$, glucose $10 \mathrm{mM}, \mathrm{CaCl}_{2} 2.5$ $\mathrm{mM}$ ) and adjusted to $\mathrm{pH}$ 7. Final anisomycin concentration was $120 \mathrm{mg} / \mathrm{mL}$.

\section{Behavioral procedures}

Saccharin $(0.1 \% \mathrm{w} / \mathrm{v})$ was used as the CS and i.p. injection of $\mathrm{LiCl}$ ( $0.15 \mathrm{M}, 1 \%$ body weight) as the US. Rats were trained over $3 \mathrm{~d}$ to 
get their daily water ration from a pipette within $15 \mathrm{~min}$ at a specific day time. On days 4 and 5 , rats were presented with saccharin instead of water for $15 \mathrm{~min}$. Fifteen minutes later they were injected i.p. with $\mathrm{LiCl}$ solution. Water was again presented for $15 \mathrm{~min} 4.5 \mathrm{~h}$ after the injection to prevent rats from dehydration. Saccharin was presented again on day 6 as a memory test. Anisomycin or ACSF (as control solution) was microinfused into the IC, BLA, CeA, IC and $\mathrm{BLA}$, or IC and CeA, as indicated in the Results section, $60 \mathrm{~min}$ before the second acquisition (on the fifth day).

In addition, to test anisomycin effects on behavioral asymptotic levels, acquisition trials were repeated until day 8 (five CTA trials, one per day), the rest of the experimental protocol remained similar to the above. Anisomycin or ACSF was injected in both the IC and CeA $60 \mathrm{~min}$ before the fifth acquisition. Saccharin was presented $24 \mathrm{~h}$ after the last acquisition as a test trial. Because of the number of aversive association trials carried out in this protocol, all animals were monitored during the behavioral experiment.

\section{Surgery and microinfusions}

Rats were anesthetized with ketamine-xylazine $(76-78 \mathrm{mg} / \mathrm{kg})$, positioned in a stereotactic apparatus, and implanted bilaterally with stainless-steel guide cannulae (30 gauge) aimed $2 \mathrm{~mm}$ above the CeA, BLA, and/or IC. CeA: AP $-2.2 \mathrm{~mm}, \mathrm{~L} \pm 4 \mathrm{~mm}, \mathrm{DV}-5.8$ $\mathrm{mm}$; BLA: AP $-2.8 \mathrm{~mm}, \mathrm{~L} \pm 5 \mathrm{~mm}, \mathrm{DV}-6.5 \mathrm{~mm}$; IC: AP $+1.2 \mathrm{~mm}$, $\mathrm{L} \pm 5.5 \mathrm{~mm}, \mathrm{DV}-4 \mathrm{~mm}$; all relative to bregma (Paxinos and Watson 1998). Cannulae were anchored with dental acrylic cement to two surgical screws fixed to the skull. Stylets were inserted into the guide cannulae to prevent them from clogging. Behavioral procedures began at least $5 \mathrm{~d}$ after surgery.

Experimental groups according to cannulae implantation and drug infusions resulted as follows: IC-V (ACSF infused, $n=$ 32 ) and IC-A (anisomycin infused, $n=33$ ) implanted in the IC; CeA-V (ACSF infused, $n=28$ ) and CeA-A (anisomycin infused, $n=$ 30) implanted in the CeA; BLA-V (ACSF infused, $n=13$ ) and BLA-A (anisomycin infused, $n=15$ ) implanted in the BLA; IC+CeA-V (ACSF infused, $n=45$ ) and IC+CeA-A (anisomycin infused, $n=46$ ) implanted in both the IC and the CeA; IC+BLA-V (ACSF infused, $n=22$ ) and IC+BLA-A (anisomycin infused, $n=29$ ) implanted in both the IC and the BLA.

For the bilateral microinfusions, an injector was inserted into each guide cannulae extending $2 \mathrm{~mm}$ below the cannula tip. A volume of $0.5 \mu \mathrm{L}(0.5 \mu \mathrm{L} / \mathrm{min})$ was injected per hemisphere in the BLA and CeA and $1 \mu \mathrm{L}$ in the IC. Animals were handled for at least $3 \mathrm{~d}$ before injection day to minimize stress.

\section{Histology}

When the experiments were finished, animals were injected with a lethal dose of pentobarbital and perfused with physiological saline solution. Brains were removed and stored in a paraformaldehyde $(4 \%)$ solution and then transferred to a $30 \%$ buffered sucrose solution and stored at $4^{\circ} \mathrm{C}$ until they were cut. Fortymicrometer thick coronal section slices were obtained and stained with Cresyl violet; sites of injection were examined under a light microscope. Sample pictures of each structure with injection placement are shown in Figure 1.

\section{Statistical analysis}

Statistical analysis was done with repeated-measures ANOVAs and post-hoc analysis with Fisher's $t$-test. For a better appreciation of the results, vehicle-injected animals are presented as a single group for Figures 2 and 3; representation of individual vehicle groups can be seen in Supplemental Figures A and B, respectively (online). However, statistical analysis was done with the corresponding control group. A probability level of $P<0.05$ was accepted as statistical significance. In the figures, the means consumption \pm SEM are expressed as a percentage of the first CTA intake.

\section{Acknowledgments}

We thank Oreste Carbajal for his technical assistance. This study was performed in partial fulfillment of the requirements of the
PhD degree in Biomedical Sciences of P.G.-D.T. at the Universidad Nacional Autónoma de México with a doctoral fellowship provided by CONACyT. This work was supported by CONACyT 60478 and DGAPA-UNAM IN220706-03.

\section{References}

Bahar A, Samuel A, Hazvi S, Dudai Y. 2003. The amygdalar circuit that acquires taste aversion memory differs from the circuit that extinguishes it. Eur J Neurosci 17: 1527-1530.

Bahar A, Dorfman N, Dudai Y. 2004. Amygdalar circuits required for either consolidation or extinction of taste aversion memory are not required for reconsolidation. Eur J Neurosci 19: 1115-1118.

Bontempi B, Laurent-Demir C, Destrade C, Jaffard R. 1999. Time-dependent reorganization of brain circuitry underlying long-term memory storage. Nature 400: 671-675.

Bures J, Bermúdez-Rattoni F, Yamamoto T. 1998. Conditioned taste aversion: Memory of a special kind. Oxford University Press, New York.

Davis HP, Squire LR. 1984. Protein synthesis and memory: A review. Psychol Bull 96: 518-559.

Dudai Y. 2002. Memory from A to Z. Keywords, concepts, and beyond. Oxford University Press, Oxford, UK.

Dudai Y. 2004. The neurobiology of consolidation, or, how stable is the engram? Annu Rev Psychol 55: 51-86.

Dudai Y. 2006. Reconsolidation: The advantage of being refocused. Curr Opin Neurol 16: 174-178.

Dudai Y, Eisenberg M. 2004. Rites of passage of the engram: Reconsolidation and the lingering consolidation hypothesis. Neuron 44: 93-100.

Dunn LT, Everitt BJ. 1988. Double dissociations of the effects of amygdala and insular cortex lesions on conditioned taste aversion, passive avoidance, and neophobia in the rat using the excitotoxin ibotenic acid. Behav Neurosci 102: 3-23.

Duvarci S, Nader K. 2004. Characterization of fear memory reconsolidation. J Neurosci 24: 9269-9275.

Eisenberg M, Kobilo T, Dudai Y. 2003. Stability of retrieved memory: Inverse correlation with trace dominance. Science 301: 1102-1104.

Eschenko O, Mölle M, Borne J, Sara SJ. 2006. Elevated sleep spindle density after learning or after retrieval in rats. J Neurosci 26: 1291412920.

Escobar ML, Alcocer I, Chao V. 1998. The NMDA receptor antagonist CPP impairs conditioned taste aversion and insular cortex long-term potentiation in vivo. Brain Res 812: 246-251.

Escobar ML, Bermúdez-Rattoni F. 2000. Long-term potentiation in the insular cortex enhances conditioned taste aversion retention. Brain Res 852: 208-212.

Escobar ML, Alcocer I, Bermúdez-Rattoni F. 2002. In vivo effects of intracortical administration of NMDA and metabotropic glutamate receptors antagonists on neocortical long-term potentiation and conditioned taste aversion. Behav Brain Res 129: 101-106.

Ferreira G, Miranda MI, De la Cruz V, Rodríguez-Ortiz CJ, Bermúdez-Rattoni F. 2005. Basolateral amygdala glutamatergic activation enhances taste aversion through NMDA receptor activation in the insular cortex. Eur J Neurosci 22: 2595-2604.

Gold PE. 2007. Protein synthesis inhibition and memory: Formation vs. amnesia. Neurobiol Learn Mem 89: 201-211.

Grossman SE, Fontanini A, Wieskopf JS, Katz DB. 2008. Learning-related plasticity of temporal coding in simultaneously recorded amygdalacortical ensembles. J Neurosci 28: 2864-2873.

Gruest N, Richer P, Hars B. 2004. Memory consolidation and reconsolidation in the rat pup require protein synthesis. J Neurosci 24: 10488-10492.

Gutiérrez H, Ramírez-Trejo L, Silva-Gandarias R, Ormsby CE, Miranda MI, Bermúdez-Rattoni F. 1999. Redundant basal forebrain modulation in taste aversion memory formation. J Neurosci 19: 7661-7669.

Höistad M, Barbas H. 2008. Sequence of information processing for emotion through pathways linking temporal and insular cortices with the amygdala. Neuroimage 40: 1016-1033.

Huff NC, Rudy JW. 2004. The amygdala modulates hippocampusdependent context memory formation and stores cue-shock associations. Behav Neurosci 118: 53-62.

Hupbach A, Gomez R, Hardt O, Nadel L. 2007. Reconsolidation of episodic memories: A subtle reminder triggers integration of new information. Learn Mem 14: 47-53.

Koh MT, Bernstein IL. 2003. Inhibition of protein kinase A activity during conditioned taste aversion retrieval: Interference with extinction or reconsolidation of a memory? Neuroreport 14: 405-407.

Lee JL. 2008. Memory reconsolidation mediated the strengthening of memories by additional learning. Nat Neurosci 11: 1264-1266.

Lee JL, Everitt BJ, Thomas KL. 2004. Independent cellular processes for hippocampal memory consolidation and reconsolidation. Science 304: 839-843. 
McGaugh JL. 1966. Time-dependent processes in memory storage. Science 153: $1351-1358$

McGaugh JL. 2000. Memory-a century of consolidation. Science 287: 248-251.

Miranda MI, Ferreira G, Ramirez-Lugo L, Bermúdez-Rattoni F. 2002. Glutamatergic activity in the amygdala signals visceral input during taste memory formation. Proc Natl Acad Sci 99: 11417-11422.

Morris RG, Inglis J, Ainge JA, Olverman HJ, Tulloch J, Dudai Y. 2006 Memory reconsolidation: Sensitivity of spatial memory to inhibition of protein synthesis in dorsal hippocampus during encoding and retrieval. Neuron 50: 479-489.

Nadel L, Moscovitch M. 1997. Memory consolidation, retrograde amnesia and the hippocampal complex. Curr Opin Neurobiol 7: 217-227.

Nader K, Hardt O. 2009. A single standard for memory: The case for reconsolidation. Natl Rev 10: 224-234.

Nader K, Schafe GE, LeDoux JE. 2000. Fear memories require protein synthesis in the amygdale for reconsolidation after retrieval. Nature 406: $722-726$.

Paxinos G, Watson C. 1998. The rat brain in stereotaxic coordinates. Academic Press, San Diego, CA.

Rodriguez-Ortiz CJ, De la Cruz V, Gutiérrez R, Bermudez-Rattoni F. 2005. Protein synthesis underlies post-retrieval memory consolidation to a restricted degree only when updated information is obtained. Learn Mem 12: 533-537.

Rodriguez-Ortiz CJ, Garcia-Delatorre P, Benavidez E, Ballesteros MA, Bermudez-Rattoni F. 2008. Intrahippocampal anisomycin infusions disrupts previously consolidated spatial memory only when memory is updated. Neurobiol Learn Mem 89: 352-359.

Rosenblum K, Meiri N, Dudai Y. 1993. Taste memory: The role of protein synthesis in gustatory cortex. Behav Neural Biol 59: 49-56.

Rossato JI, Bevilaqua LRM, Myskiw JC, Medina JH, Izquierdo I, Cammarota M. 2007. On the role of hippocampal protein synthesis in the consolidation and reconsolidation of object recognition memory. Learn Mem 14: 36-46.

Sara SJ. 2000. Retrieval and reconsolidation: Toward a neurobiology of remembering. Learn Mem 7: 73-84.

Suzuki A, Josselyn SA, Frankland PW, Masushige S, Silva AJ, Kida S. 2004. Memory reconsolidation and extinction have distinct temporal and biochemical signatures. J Neurosci 24: 4787-4795.

Tronson NC, Taylor JR. 2007. Molecular mechanisms of memory reconsolidation. Nat Rev Neurosci 8: 262-275.

Yamamoto T. 2007. Brain regions responsible for the expression of conditioned taste aversion in rats. Chem Senses 32: 105-109.

Yamamoto T, Fujimoto Y. 1991. Brain mechanisms of taste aversion learning in the rat. Brain Res Bull 27: 403-406.

Yasoshima Y, Yamamoto T. 1998. Short-term and long-term excitability changes of the insular cortical neurons after the acquisition of taste aversion learning in behaving rats. Neuroscience 84: 1-5.

Received January 29, 2009; accepted in revised form July 2, 2009. 


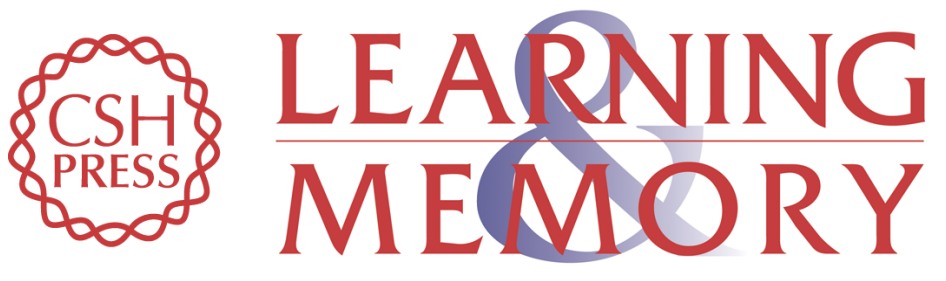

\section{Simultaneous but not independent anisomycin infusions in insular cortex and amygdala hinder stabilization of taste memory when updated}

Paola García-DeLaTorre, Carlos J. Rodriguez-Ortiz, Jose L. Arreguin-Martinez, et al.

Learn. Mem. 2009, 16:

Access the most recent version at doi:10.1101/lm.1356509

Supplemental Material

References License

Email Alerting Service
http://learnmem.cshlp.org/content/suppl/2009/09/04/16.9.514.DC1

This article cites 42 articles, 15 of which can be accessed free at: http://learnmem.cshlp.org/content/16/9/514.full.html\#ref-list-1

Receive free email alerts when new articles cite this article - sign up in the box at the top right corner of the article or click here. 